\title{
Changes in (markers of) bone metabolism during high dose corticosteroid pulse treatment in patients with rheumatoid arthritis
}

\author{
W F Lems, M I Gerrits, J W G Jacobs, R M van Vugt, H J M van Rijn, J W J Bijlsma
}

\begin{abstract}
Objective-To examine the effect of high dose corticosteroid pulse treatment (three times $200 \mathrm{mg}$ dexamethasone intravenously in eight days) on calcium and bone metabolism in 17 consecutive patients with active rheumatoid arthritis (RA).

Methods-Bone formation was quantified by measurement of serum alkaline phosphatase, osteocalcin, and carboxyterminal propeptide of type I procollagen (pro-I-CPP) concentrations. Bone resorption was measured by urinary excretion of calcium, hydroxyproline, (free and total) deoxypyridinoline (Dpyr), (free and total) pyridinoline (Pyr), and serum concentrations of the carboxyterminal cross linked telopeptide of type I collagen (I-CTP). Disease activity of RA was measured by erythrocyte sedimentation rate, $C$ reactive protein, and Ritchie and Thompson joint scores.
\end{abstract}

Results-Disease activity was initially high, and decreased during corticosteroid pulse treatment and the following five weeks. Osteocalcin, alkaline phosphatase, and pro-I-CPP concentrations were initially within normal limits, while I-CTP, Dpyr, and Pyr were increased. Osteocalcin and pro-I-CPP concentrations decreased $(\mathbf{p}<0.01)$ during corticosteroid pulse treatment, but rapidly returned to baseline after the treatment. No changes were observed in alkaline phosphatase and urinary excretion of calcium and hydroxyproline. Bone resorption measured by serum I-CTP and urinary excretion of Pyr and Dpyr was unchanged or decreased (p< 0.05-0.01), depending on the time of measurement and the parameter measured.

Conclusions-In these patients with active RA, bone resorption was increased, while bone formation was within normal limits. During high dose corticosteroid pulse treatment, bone formation was only transiently decreased, while markers of bone resorption were unchanged or decreased. Because corticosteroid pulse treatment has only a short term negative effect on bone formation, and because it probably reduces bone resorption, at least partly as a result of the decreased disease activity, the effect of corticosteroid pulse treatment on bone may be assumed to be relatively mild.

(Ann Rheum Dis 1996; 55: 288-293)

One of the most important side effects of long term use of corticosteroids is osteoporosis, ${ }^{1-3}$ characterised by decreased bone formation and unchanged or increased bone resorption. This uncoupling of bone formation and bone resorption may lead to bone loss, ${ }^{1-3}$ and eventually to fractures. ${ }^{4-6}$

In some patients with rheumatoid arthritis (RA), corticosteroid pulse treatment is used during the delay between the introduction of disease modifying antirheumatic drugs (DMARDs) and the onset of their therapeutic effect, or in patients with extra-articular complications who fail to respond to conventional long term treatment. ${ }^{7}$

In our previous studies on calcium and bone metabolism during corticosteroid pulse treatment, we used urinary calcium and hydroxyproline excretion as markers of bone resorption, and serum alkaline phosphatase as a marker of bone formation. ${ }^{8-10}$ Two new serum markers of bone metabolism have since been introduced: the carboxyterminal propeptide of type I procollagen (pro-I-CPP) and the carboxyterminal cross linked telopeptide of type I collagen (I-CTP). Pro-I-CPP reflects the synthesis of type I collagen and is a marker of bone formation, ${ }^{11}$ while I-CTP is liberated during the degradation of type I collagen and is regarded as a serum marker of bone resorption. ${ }^{12}$ Pyridinoline (Pyr) and deoxypyridinoline (Dpyr) are two recently developed urinary markers of bone resorption $^{13}{ }^{14}$ that are non-reducible cross links of collagen: Dpyr is derived from bone and dentin; Pyr is also derived from cartilage, synovium, and tendons. Compared with the conventional quantification of bone resorption by measurement of hydroxyproline, important advantages of the pyridinolines are that they are not metabolised, and the diet does not influence their measurement. ${ }^{15}$

In this study, we compared the effect of corticosteroid pulse treatment on bone formation as quantified by measurement of serum alkaline phosphatase, osteocalcin, and pro-I-CPP, and the effect on bone resorption 
as quantified by the urinary excretion of calcium, hydroxyproline, Pyr, Dpyr, and serum I-CTP.

\section{Patients and methods}

Seventeen consecutive patients (six pre- and six postmenopausal women, and five men) with active RA according to the 1987 American Rheumatism Association criteria ${ }^{16}$ and of mean age 56 years (range 28-77 years) were studied. The mean duration of their RA was 9 (SD 9) years. Four of the patients were taking corticosteroids on a daily basis $(10 \mathrm{mg} /$ day prednisone or less, in a stable dosage). Thirteen had bone erosions. Thirteen were taking DMARDs. All patients gave informed consent to participate in the study, which was approved by the Medical Ethics Committee of the University Hospital Utrecht. The patients were admitted to hospital (day 0 ) and received three times $200 \mathrm{mg}$ dexamethasone intravenously over 30 minutes on day 2 (after blood and urine were collected) and on days 5 and 8. Blood and fasting urine samples (second morning void) were collected early in the morning. Two blood and urine samples were taken before the corticosteroid pulse treatment (day 1 and day 2), and were regarded as baseline. Further blood and urine collections were performed on days $3,4,5$, and 8 , and two, four, and six weeks after the pulse treatment had started. The last three measurements were performed on an outpatient basis. As indicators of RA disease activity, joint scores (Ritchie and Thompson score) were assessed on day 1 (before the first pulse), on day 4 (before the second pulse), on day 7 (before the third pulse), and two, four, and six weeks after corticosteroid pulse treatment, erythrocyte sedimentation rate (ESR) and $C$ reactive protein (CRP) were measured, and blood samples were tested for rheumatoid factor.

The samples were divided for the different determinations and frozen at $-20^{\circ} \mathrm{C}$ until assay. All measurements were made twice. Total osteocalcin was determined using a new human specific immunoradiometric assay (IRMA) (ELSA-OSTEO; Cis Biointernational, Bagnols, France) which recognises a large $\mathrm{N}$-terminal mid-fragment in addition to the intact molecule. Normal values for postmenopausal women are $24.4 \mathrm{ng} / \mathrm{ml}$ (range 12.9-55.9), according to the manufacturer, and intra- and interassay coefficients of variation were $3 \cdot 1 \%$ and $1 \cdot 8 \%$, respectively. ${ }^{17}$ In vitro measurement of pro-I-CPP and I-CTP was by radioimmunoassay (Orion Diagnostica, Finland). According to the manufacturer, normal values are $50-220 \mu \mathrm{g} / \mathrm{l}$ for pro-I-CPP and $1 \cdot 7-5 \cdot 0 \mu \mathrm{g} / \mathrm{l}$ for I-CTP, and the intra- and interassay coefficients of variation are $3 \%$ and $5 \%$ for pro-I-CPP and $4 \%$ and $6 \%$ for I-CTP. Pyr and Dpyr were determined as free and as total Pyr and Dpyr. To determine the total fraction, the urine was hydrolysed in $6 \mathrm{~mol} / \mathrm{l}$ hydrochloric acid at $110^{\circ} \mathrm{C}$ for 18 hours, and extraction performed by cellulose CF 1 column chromatography. The extraction product was freeze-dried before separation by high performance liquid chromatography on a reverse phase C18 column, and identified by spectrofluorimetry. ${ }^{18}$ In our laboratory, normal values for healthy persons aged 22-64 years were $11.3 \mu \mathrm{mol} / \mathrm{mol}$ creatinine (range 5.9-36.2) for free Pyr, $3.6 \mu \mathrm{mol} / \mathrm{mol}$ creatinine (range 1.0-13.5) for free Dpyr, $24.2 \mu \mathrm{mol} / \mathrm{mol}$ creatinine (range 13.5-53.2) for total Pyr, and $7 \cdot 1 \mu \mathrm{mol} / \mathrm{mol}$ creatinine (range $2 \cdot 2-27 \cdot 6$ ) for total Dpyr. These data are comparable to others in the literature. ${ }^{19}$ In our laboratory, the intra-assay coefficients of variation for pyridinoline is less than $10 \%$, and the interassay coefficient of variation is less than $12 \cdot 5 \% .^{18}$

Serum alkaline phosphatase, calcium, creatinine, and inorganic phosphorus were measured on a Hitachi 717 autoanalyser using Boehringer-Mannheim Reagents (Germany). Intact parathyroid hormone (PTH) was measured with an IRMA from Nichols institute (San Juan Capistrano, California USA). Calcium in urine was measured colorimetrically on a Technicon RA-1000 Autoanalyzer. Hydroxyproline in the urine was measured using Hypronosticon (Organon, the Netherlands). All data obtained from urinary assays were corrected by the creatinine concentration measured by a standard colorimetric method.

\section{STATISTICS}

Statistical analysis was carried out with Number Cruncher Statistical System (NCSS) software package version 5.1. For the comparison of data with normal distribution, paired $t$ tests were used, and for those not normally distributed, the Wilcoxon rank sum test was used. All statistical tests were twosided. A value of $p<0.05$ was considered to be statistically significant. The relationship between markers of bone metabolism and disease activity was examined by Spearman correlations.

\section{Results}

Table 1 shows details of the patients before they commenced high dose corticosteroid treatment.

Initially, all patients had active $\mathrm{RA}$, as shown by the increased ESR and CRP, and high

Table 1 Details of the 17 patients with $R A$ before the start of high dose corticosteroid treatment

\begin{tabular}{lc}
\hline Rheumatoid factor & \\
No positive & 12 \\
Titre & $288(394)$ \\
Erythrocyte sedimentation & $72(42)$ \\
rate $(\mathrm{mm} / 1 \mathrm{st} \mathrm{h})$ & $63(52)$ \\
C reactive protein $(\mathrm{mg} / \mathrm{l})$ & $295(179)$ \\
Joint scores & $19(12)$ \\
Thompson & 15 \\
Ritchie & 2 \\
Steinbrocker class & \\
2 & 5 \\
3 & 3 \\
Use of DMARDs ( $=13)$ & 4 \\
Methotrexate & 1 \\
Hydroxychloroquine & 1 \\
Salazopyrine & \\
D-penicillamine & \\
Azathioprine & \\
\hline
\end{tabular}

Values are number or mean (SD). 


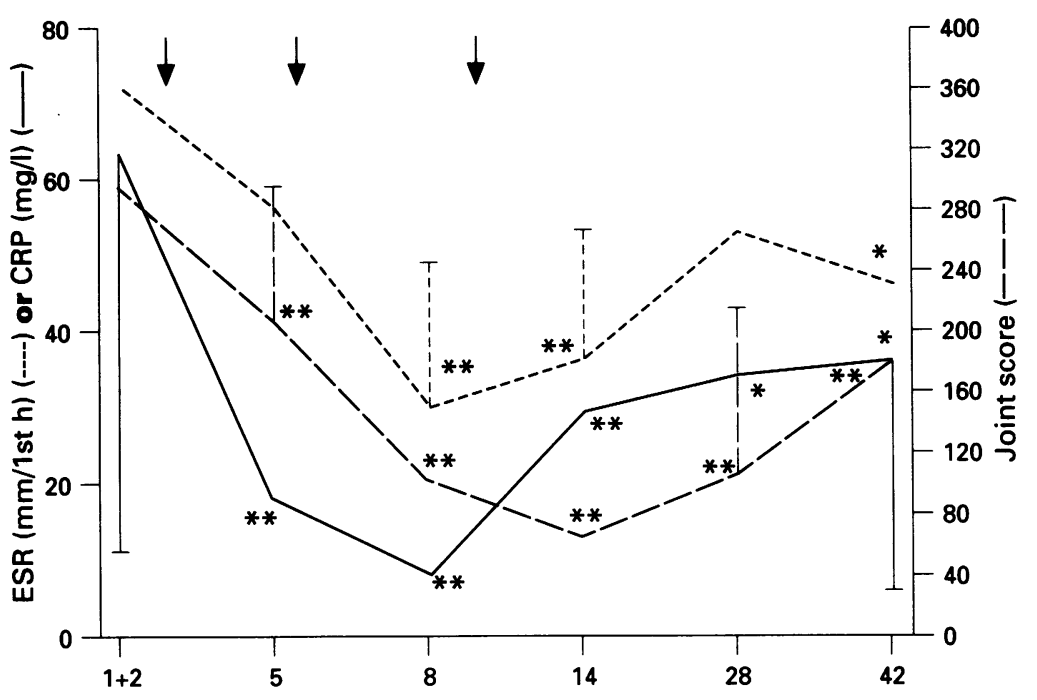

Day

Figure 1 Effect of high dose corticosteroid pulse treatment (intravenous infusion of $200 \mathrm{mg}$ dexamethasone on days 2,5 , and 8 ( 1$)$ ) on erythrocyte sedimentation rate (ESR), $C$ reactive protein (CRP), and Thompson joint score in patients with active $R A .{ }^{\star} p<0.05$, ${ }^{\star \star} p<0.01$ compared with baseline.

Ritchie and Thompson scores at baseline (fig 1; data on Ritchie score not shown). All patients had a good clinical response during the corticosteroid pulse treatment (fig 1). At the end of the study, six weeks after corticosteroid pulse treatment started, disease activity remained depressed. None of the patients had serious side effects. Initially, osteocalcin, alkaline phosphatase and pro-I-CPP were all in the normal range (fig 2). Urinary excretion of Pyr and Dpyr, and serum I-CTP concentration were increased before the start of corticosteroid pulse treatment (table 2). At the start of treatment, osteocalcin and pro-I-CPP were not correlated with ESR and CRP, but free Pyr was correlated with ESR $(r=0.58 ; \mathrm{p}<0.05)$ and with CRP $(r=0.77 ; \mathrm{p}<0.01)$ and free Dpyr was also correlated with ESR $(r=0.57$; $\mathrm{p}<0.05)$ and CRP $(r=0.65 ; \mathrm{p}<0.01)$. Serum I-CTP was correlated with CRP $(r=0.50$; $\mathrm{p}<0.05$ ), but not with ESR.

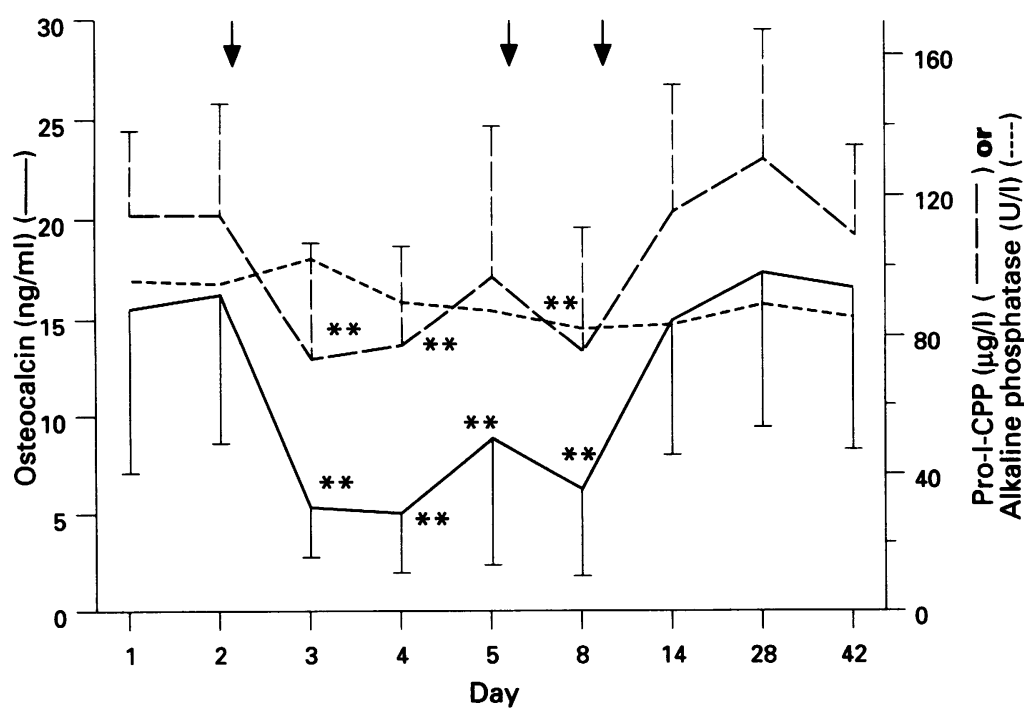

Figure 2 Effect of high dose corticosteroid pulse treatment (intravenous infusion of $200 \mathrm{mg}$ dexamethasone on days 2,5 , and $8(1))$ on markers of bone formation in patients with active RA. Pro-I-CPP = carboxyterminal propeptide of type I procollagen. ${ }^{\star} p<0.05$, ${ }_{\star \star} p<0.01$ compared with baseline.
During pulse treatment, there was decrease in osteocalcin at days $3,4,5$, and $8(p<0.01)$ (fig 2 ) and in pro-I-CPP at days 3,4 , and 8 $(\mathrm{p}<0.01$ ) (fig 2 ). The serum values of alkaline phosphatase tended to decrease, but these changes were not statistically significant. I-CTP was also decreased at days $3,4,5$, and 8 of corticosteroid pulse treatment $(p<0.01)$ (fig 3). Urinary excretion of free Dpyr and free Pyr was decreased only on day $8(p<0.01)$ (table 2), but urinary excretion of total Dpyr remained decreased at 2,4 , and 6 weeks after pulse treatment started (table 2, fig 3 ). The urinary excretion of calcium and hydroxyproline remained unchanged (data not shown). Serum calcium was increased the day after pulse treatment started but decreased three days after the start (table 2). PTH was slightly increased during pulse treatment, and returned to baseline after it (changes not statistically significant) (table 2). No changes occurred in creatinine and inorganic phosphorus concentrations (data not shown).

Two, four, and six weeks after the start of corticosteroid pulse treatment, all markers of bone metabolism, except total Dpyr, had returned to baseline values (table 2 , figs 2,3 ).

\section{Discussion}

\section{EFFECT OF CORTICOSTEROID PULSE}

TREATMENT ON RA

All patients had high disease activity of RA at baseline, and this was correlated with markers of bone resorption, but not of bone formation. As early as three days after the pulse treatment was started, there was a substantial corticosteroid induced decrease in disease activity. Disease activity remained decreased for the entire study period of six weeks. This can be attributed to the effects of the corticosteroid pulse treatment, and in the later weeks perhaps also to DMARD treatment: though the clinical efficacy of DMARDs is usually not evident before six weeks of treatment, a small effect on disease activity cannot be excluded.

EFFECT OF CORTICOSTEROID PULSE TREATMENT ON (MARKERS OF) BONE FORMATION

Initially, the concentrations of osteocalcin, alkaline phosphatase and pro-I-CPP were within normal ranges. In an earlier study in patients with $R A,{ }^{20}$ we observed that serum osteocalcin was slightly increased, which was probably related to a greater disease activity in that study. ${ }^{20}$ The decreases in osteocalcin and pro-I-CPP during corticosteroid pulse treatment in the present study were both statistically significant, while that in alkaline phosphatase was not. This indicates that alkaline phosphatase is a less sensitive marker of rapidly occurring changes in bone formation, which confirmed our earlier results. ${ }^{20}$ Bone specific alkaline phosphatase is probably a more sensitive marker of changes in bone formation, ${ }^{21}$ but was not measured in the present study. Two weeks after the start of pulse treatment, osteocalcin and pro-I-CPP 
Table 2 Effect of high dose corticosteroid pulse treatment on parathyroid hormone (PTH) and (markers of) bone resorption in patients with rheumatoid arthritis

\begin{tabular}{|c|c|c|c|c|c|c|c|c|c|}
\hline & $\begin{array}{l}\text { (Pulse 1) } \downarrow \\
\text { Day 1+2 }\end{array}$ & Day 3 & Day 4 & $\begin{array}{c}\text { (Pulse 2) } \\
\text { Day } 5\end{array}$ & Day 8 & $\downarrow \frac{\text { (Pulse 3) }}{\text { Day } 14}$ & Day 28 & Day 42 & $\begin{array}{l}\text { Normal } \\
\text { values }\end{array}$ \\
\hline PTH (pmol/) & $\begin{array}{l}1.02 \\
(0 \cdot 24)\end{array}$ & $\begin{array}{l}1 \cdot 02 \\
(0 \cdot 21)\end{array}$ & $\begin{array}{l}1.06 \\
(0 \cdot 21)\end{array}$ & $\begin{array}{l}1 \cdot 12 \\
(0 \cdot 23)\end{array}$ & $\begin{array}{l}1 \cdot 12 \\
(0 \cdot 29)\end{array}$ & $\begin{array}{l}0.96 \\
(0 \cdot 19)\end{array}$ & $\begin{array}{l}0.96 \\
(0.19)\end{array}$ & $\begin{array}{l}0.95 \\
(0.21)\end{array}$ & $<7 \dagger$ \\
\hline $\begin{array}{l}\text { Pyridinoline } \\
\text { Free }(\mu \mathrm{mol} / \mathrm{mol} \\
\text { creatinine }) \\
\text { Total }(\mu \mathrm{mol} / \mathrm{mol} \\
\text { creatinine }) \\
\text { Free/total }\end{array}$ & $\begin{array}{l}35 \cdot 2 \\
(24 \cdot 9) \\
106 \\
(96) \\
0 \cdot 33\end{array}$ & $\begin{array}{l}34 \cdot 9 \\
(21 \cdot 6) \\
111 \cdot 3 \\
(118) \\
0 \cdot 31\end{array}$ & $\begin{array}{l}33 \cdot 8 \\
(22 \cdot 3) \\
108 \\
(121) \\
0.31\end{array}$ & $\begin{array}{l}28 \cdot 9 \\
(21 \cdot 6) \\
86 \cdot 1 \\
(95) \\
0 \cdot 34\end{array}$ & $\begin{array}{l}23 \cdot 8^{\star \star} \\
(16 \cdot 0) \\
75 \cdot 6 \\
(73) \\
0 \cdot 31\end{array}$ & $\begin{array}{l}31 \cdot 3 \\
(21 \cdot 4) \\
82 \cdot 7 \\
(70) \\
0 \cdot 38\end{array}$ & $\begin{array}{l}33 \cdot 8 \\
(21 \cdot 4) \\
80 \cdot 9 \\
(58) \\
0 \cdot 42\end{array}$ & $\begin{array}{l}33 \cdot 7 \\
(15 \cdot 8) \\
83 \cdot 8^{\star} \\
(32) \\
0 \cdot 40\end{array}$ & $\begin{array}{l}11 \cdot 3 \\
(5 \cdot 9-36 \cdot 2) \\
24 \cdot 2 \\
(13 \cdot 5-53 \cdot 2)\end{array}$ \\
\hline $\begin{array}{l}\text { Deoxypyridinoline } \\
\text { Free }(\mu \mathrm{mol} / \mathrm{mol} \\
\text { creatinine }) \\
\text { Total }(\mu \mathrm{mol} / \mathrm{mol} \\
\text { creatinine } \\
\text { Free/total } \\
\text { I-CTP }(\mu \mathrm{g} /)\end{array}$ & $\begin{array}{l}7 \cdot 1 \\
(5 \cdot 5) \\
19 \cdot 8 \\
(15) \\
0 \cdot 35 \\
9 \cdot 3 \\
(5 \cdot 2)\end{array}$ & $\begin{array}{l}7.9 \\
(5 \cdot 4) \\
19 \cdot 5 \\
(14) \\
0 \cdot 40 \\
5 \cdot 3^{\star \star} \\
(2 \cdot 5)\end{array}$ & $\begin{array}{l}8 \cdot 3 \\
(6 \cdot 3) \\
17 \cdot 1 \\
(15) \\
0 \cdot 48 \\
6 \cdot 4^{\star \star} \\
(3 \cdot 3)\end{array}$ & $\begin{array}{l}6 \cdot 1 \\
(5 \cdot 4) \\
15 \\
(12) \\
0 \cdot 41 \\
7 \cdot 6^{\star} \\
(2 \cdot 9)\end{array}$ & $\begin{array}{l}4 \cdot 9^{\star \star} \\
(3 \cdot 6) \\
12 \cdot 9^{\star} \\
(11) \\
0 \cdot 38 \\
7 \cdot 2^{\star \star} \\
(7 \cdot 2)\end{array}$ & $\begin{array}{l}6 \cdot 3 \\
(4 \cdot 5) \\
11 \cdot 8^{\star \star} \\
(9) \\
0 \cdot 53 \\
7 \cdot 6 \\
(4 \cdot 6)\end{array}$ & $\begin{array}{l}7 \cdot 1 \\
(4 \cdot 9) \\
13 \cdot 3^{\star} \\
(9) \\
0 \cdot 53 \\
7 \cdot 3 \\
(5 \cdot 2)\end{array}$ & $\begin{array}{l}0.20 \\
6 \cdot 2 \\
(2 \cdot 6) \\
14 \cdot 1^{\star} \\
(7) \\
0.43 \\
7 \cdot 4 \\
(5 \cdot 9)\end{array}$ & $\begin{array}{l}3 \cdot 6 \\
(1 \cdot 0-13 \cdot 5) \\
7 \cdot 1 \\
(2 \cdot 2-27 \cdot 6) \\
1 \cdot 8-5 \cdot 0\end{array}$ \\
\hline
\end{tabular}

Values are mean (SD) or mean (range). $†$ Normocalcaemia.

I Dexamethasone $200 \mathrm{mg}$ intravenous pulse. I-CTP = Cross linked telopeptide of type I collagen.

${ }^{\star} \mathrm{p}<0.05,{ }^{\star \star} \mathrm{p}<0.01$, compared with baseline.

had already returned to baseline, indicating, in accordance with earlier reports, ${ }^{20} 22$ that inhibition of bone formation by corticosteroid pulse treatment was only transient. On the basis of these results, both osteocalcin and proI-CPP seem to be reliable parameters of bone formation for monitoring patients treated with corticosteroids.

The day after the start of corticosteroid pulse treatment, serum calcium was increased, but three days after the start it had decreased. These changes in serum calcium confirm earlier results; ${ }^{8}$ the initial increase in serum calcium is probably the result of sodium retention induced by high doses of corticosteroids, while the subsequent decrease is believed to reflect decreased intestinal absorption of calcium and increased renal excretion of calcium induced by corticosteroids. The decrease in serum calcium is accompanied by a tendency (not statistically significant) to an increase in PTH concentration during corticosteroid pulse treatment, ${ }^{7-9}$ and is followed by

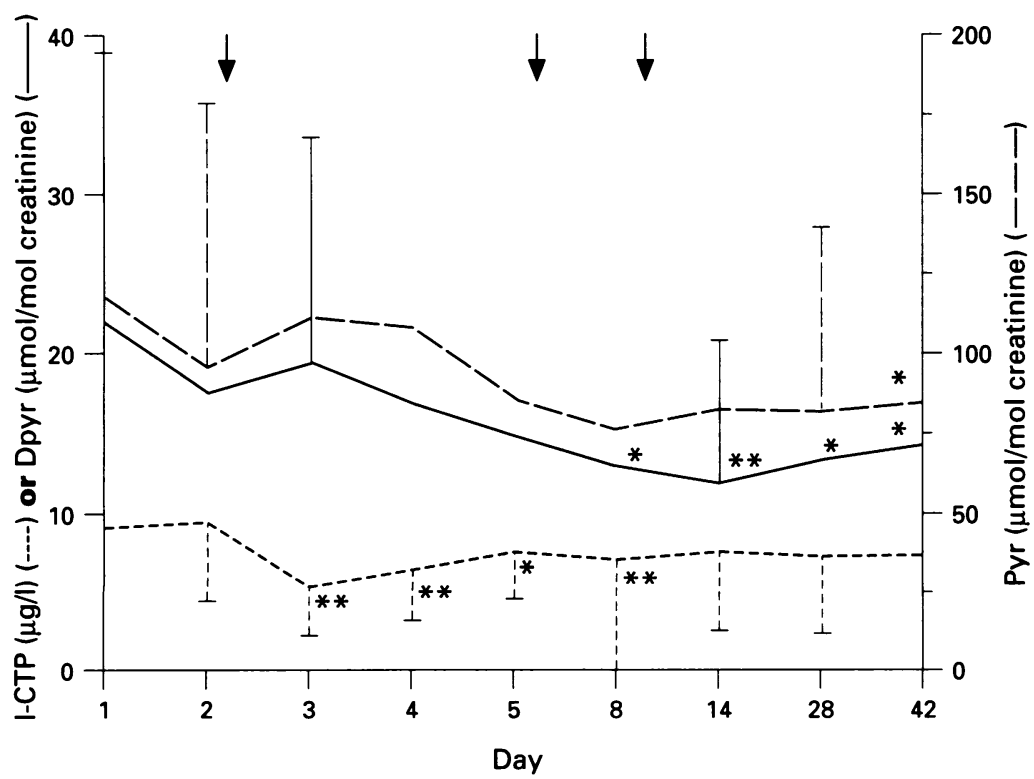

Figure 3 Effect of high dose corticosteroid pulse treatment (intravenous infusion of $200 \mathrm{mg}$ dexamethasone on days 2,5 , and $8(1)$ ) on markers of bone resorption in patients with active $R A$. I-CTP = Carboxyterminal cross linked telopeptide of type I collagen; Pyr = urinary excretion of (total) pyridinoline; Dpyr = urinary excretion of (total) deoxypyridinoline. ${ }^{\star} p<0.05,{ }^{\star \star} p<0.01$, compared with baseline. a return to baseline concentrations of both calcium and PTH after the treatment.

EFFECT OF CORTICOSTEROID PULSE TREATMENT ON (MARKERS OF) BONE RESORPTION

At baseline, serum I-CTP and urinary excretion of Pyr (free and total) and Dpyr (free and total) in our patient group were greatly in excess of the normal range. This indicates that bone resorption was high in these patients with active RA, which is in accordance with the findings of earlier studies. ${ }^{2023}$ These data confirm the discrepancy between increased bone resorption and normal bone formation in patients with $R A,{ }^{24}{ }^{25}$ that is also reflected in the observation at baseline that (markers of) bone resorption were correlated with disease activity, while markers of bone formation were not.

During and after corticosteroid pulse treatment, serum I-CTP and urinary excretion of Pyr (free and total) and Dpyr (free and total) were, depending on the time of measurement and the parameter measured, unchanged or decreased. This is interesting, because it is in contrast with the observation that the use of high dose corticosteroids may lead to (relatively or absolutely) increased bone resorption. ${ }^{1-3} 26$ Unfortunately, it is not possible to discriminate between an effect on bone resorption induced by high dose corticosteroids and an indirect inhibitory effect on bone resorption as a result of decreased activity of RA. As bone resorption tended to decrease rather than to increase, the indirect effect mediated by disease activity is probably stronger than the effect of corticosteroids. Bone resorption did not return to normal values after pulse treatment, probably as a result of persisting disease activity of RA.

The present study confirms the decrease in I-CTP one week after the start of pulse treatment, ${ }^{21}$ and the relatively stable Pyr and Dpyr concentrations ${ }^{23}$ four weeks after the start of corticosteroid pulse treatment. The observation that these markers were decreased at different times of measurement possibly reflects that they are measures of different things: I-CTP is a measure of collagen type I 
degradation that is common in bone, Pyr is a measure of degradation of bone, cartilage, and synovium, and Dpyr measures degradation predominantly of bone, but also of dentin and tendons. A corticosteroid induced difference in collagen catabolism and metabolism may also explain the difference between changes in I-CTP and Pyr or Dpyr. Interestingly, Dpyr was the only marker of bone resorption that was decreased during the entire study period of six weeks.

Theoretically, the changes in $\mathrm{Pyr}$ are expected to be greater than those in Dpyr, because urinary excretion of Pyr results not only from bone resorption, but also from cartilage and synovial degradation. However, this was not observed in the present study, or in earlier cross-sectional studies in patients with osteoarthritis ${ }^{27}$ and $\mathrm{RA}^{29}{ }^{30}$ in which both Pyr and Dpyr were increased. This suggests that increased Pyr concentrations originate primarily from bone, probably because cartilage is less abundant and less metabolically active than bone. As both cross links derive from a post-translational modification of collagen molecules already secreted and incorporated into the intracellular matrix, they cannot be reutilised during collagen synthesis. ${ }^{13}$ Moreover, Pyr and Dpyr are not metabolised, and their measurement, in contrast to that of hydroxyproline, is not influenced by diet. ${ }^{15}$ It has been shown that the urinary excretion of cross links is not only a more specific, ${ }^{21}$ but also a more sensitive marker of bone resorption than that of hydroxyproline. ${ }^{31} 32$

It is assumed that approximately $40 \%$ of the urinary cross links are excreted in free form, while the remaining $60 \%$ are found incorporated into peptides of various length. ${ }^{13}{ }^{14}$ In the present study, the ratio of free to total Dpyr changed from $35 \%$ to $53 \%$. Recently, it has been shown that increased bone turnover in patients with metabolic diseases (Paget's disease, hyperthyroidism) may result in a larger increase of the total fraction compared with free cross links. ${ }^{33}$ In the present study, we also observed that the ratio of free to total Pyr and Dpyr was smallest at the start of corticosteroid pulse treatment, when bone metabolism (resorption) was high. As the metabolic background of this difference is unclear, it cannot be assumed that analysis of the free fraction of pyridinolines will necessarily give the same information as analysis of the total fraction. ${ }^{34}$ It has recently become possible to measure the free fraction of pyridinolines by immunoassay. ${ }^{35}$ One advantage of immunoassay is that it is easier to perform, but, theoretically, the advantage of HPLC is that with this technique both free and total pyridinolines can be measured.

An advantage of I-CTP compared with other markers of bone resorption is that it can be measured in serum; $;^{11}$ measurement of urinary excretion may be inaccurate because of low patient compliance or collection errors. In patients with multiple myeloma, I-CTP was decreased during (cytostatic) treatment and increased upon recurrence of the disease. ${ }^{37}$
However, in a study of postmenopausal women with active RA treated with hormonal replacement therapy in whom bone density increased, the expected decrease in I-CTP was not observed, suggesting that I-CTP is probably less sensitive for changes in bone metabolism. ${ }^{38}$

\section{EFFECT OF CORTICOSTEROID PULSE}

TREATMENT ON BONE

Although it is well known that the use of corticosteroids is associated with bone loss ${ }^{1-3}$ and fractures, ${ }^{4-6}$ the effect of corticosteroid pulse treatment on bone has not been extensively examined. To our knowledge, no data exist on the effect of corticosteroid pulse treatment on bone mass or bone strength. In the present study, we examined the effect of this treatment on recently developed, more reliable markers of bone metabolism. In these patients with active RA, bone resorption was increased, while bone formation was within normal limits. During high dose corticosteroid pulse treatment bone formation was only transiently decreased, while markers of bone resorption were unchanged or decreased. We conclude that, because corticosteroid pulse treatment has only a short term negative effect on bone formation and probably also reduces bone resorption, at least partly as a result of decreased disease activity, the effect of corticosteroid pulse treatment on bone is relatively mild.

Dr Lems is supported by a grant from the Dutch League Against Rheumatism: Het Nationaal Reumafonds.

1 Lukert B P, Raisz L G. Glucocorticoid-induced osteoporosis: pathogenesis and management. Ann Intern Med 1990; 112: 352-64.

2 Adachi J D, Bensen W G, Hodsman A B. Corticosteroidinduced osteoporosis. Semin Arthritis Rheum 1993; 22: 375-84.

3 Sambrook P N, Jones G. Corticosteroid osteoporosis. $\mathrm{Br} \mathcal{F}$ Rheumatol 1995; 34: 8-12.

4 Adinoff A D, Hollister J R. Steroid-induced fractures and bone loss in patients with asthma. N Engl f Med 1983; 309: $265-8$

5 Dyckman T R, Gluck O S, Murphy W A, Hahn T J, Hahn B H. Evaluation of factors associated with glucocorticoid-induced ostopenia in patients with glucocorticoid-induced ostopenia in patients wits

6 Lems W F, Jahangier Z N, Jacobs J W G, Bijlsma J W J. Vertebral fractures in patients with rheumatoid arthritis treated with corticosteroids. Clin Exp Rheumatol 1995; 13 293-7.

7 Weusten B, Jacobs J W G, Bijlsma J W J. Corticosteroid pulse therapy in active rheumatoid arthritis. Semin Arthritis Rheum 1993; 23: 183-92.

8 Bijlsma J W J, Duursma S A, Huber-Bruning O. Bone metabolism during methylprednisolone pulse therapy in rheumatoid arthritis. Arthritis Rheum Dis 1986; 45: 757-60.

9 Bijlsma J W J, Duursma S A, Bosch R, Raymakers J A, Huber-Brunin $O$. Acute changes in calcium and bone metabolism during methylprednisolone pulse therapy in metabolism during methylprednisolone pulse therapy

10 Veen M J van der, Bijlsma J W J. Effects of different regimes of corticosteroid treatment on calcium and bone of corticosteroid treatment on calcium and bone 11: 402-5.

11 Risteli J, Melkko J, Niemi S, Risteli L. Use of a marker of collagen formation in osteoporosis studies. Calcif Tissue Int 1991; 49 (suppl): 24-5.

12 Risteli J, Elomma I, Niemi S, Novamo A, Risteli L Radioimmunoassay for the pyridinoline cross-linked carboxy-terminal telopeptide of type 1 collagen: a new serum marker of bone collagen degradation. Clin Chem 1993; 39: 635-40.

13 Eyre D. New markers of bone resorption. 7 Clin Endocrinol Metab 1992; 74: 470-1.

14 Editorial. Pyridinium crosslinks as markers of bone resorption. Lancet 1992; 340: 278-9.

15 Colwell A, Russell R G G, Eastell R. Factors affecting the assay of urinary 3-hydroxy-pyridinium crosslinks of assay of urinary 3-hydroxy-pyridinium crosslinks of 1993; 23: 341-9. 
16 Amett F C, Edworthy S M, Bloch D E, et al. The American Rheumatism Association 1987 revised criteria for the classification of rheumatoid arthritis. Arthritis Rheum 1988; 31: 315-24.

17 Garnero P, Grimaux M, Demiaux B, Preaudat C, Seguin P, Delmas P D. Measurement of serum osteocalcin with a human specific two-site immunoradiometric assay. $\mathcal{F}$ Bone Miner Res 1992; 7: 1389-98.

18 Gerrits M I, Thijssen J H H, van Rijn H J M. Determination of the bone resorption markers pyridinoline and deoxypyridinoline in urine, with special attention to deoxypyridinoline in urine, with special attention

19 Seibel M J, Robins S P, Bilezikian J P. Urinary crosslinks of collagen. Trends Endocrinol Metab 1992; 3: 263-70.

20 Lems W F, Jacobs J W G, Brink H R van den, Rijn H J M van, Bijlsma J W J. Transient decrease in osteocalcin and markers of collagen type 1 formation during corticosteroid pulse therapy. $\mathrm{Br} \mathcal{f}$ Rheumatol 1993; 32: 787-90.

21 Delmas P D. Biochemical markers of bone turnover. $\mathcal{f}$ Bone Miner Res 1993; 8: S549-55.

22 Cosman F, Nieves J, Herbert J, Shen V, Lindsay R. High dose glucocorticoids in multiple sclerosis patients exert direct effects on the kidney and skeleton. $\mathcal{f}$ Bone Miner Res direct effects on the

23 Kollerup G, Hansen M, Horslev Petersen K. Urinary hydroxypyridinium cross-links of collagen in rheumatoid arthritis. Br F Rheumatol 1994; 33: 816-20.

24 Eggelmeijer F, Papapoulos S E, Westedt M L, Paassen H C van, Dijkmans B A C, Breedveld F C. Bone metabolism in theumatoid arthritis; relation to disease activity. Br F Rheumatol 1993; 32: 387-91.

25 Hall G M, Spector T D, Delmas P D. Markers of bone metabolism in postmenopausal women with rheumatoid metabolism in postmenopausal women with.

26 Meunier P J, Dempster D W, Edouard C, Chapuy M C, Arlot $M$, Chardhon $S$. Bone histomorphometry in Arlot M, Chardhon $\mathrm{S}$. Bone histomorphometry in corticosteroid-induced osteoporosis in Cushing'

27 Thompson P W, Spector T D, James I T, Henderson E, Hart D J. Urinary collagen crosslinks reflect the radiographic severity of knee osteoarthritis. $\mathrm{Br} \mathcal{F}$ Rheumatol 1992; 31: 759-61.
28 McDonald A G, McHenry P, Robins S P, Reid D M. Relationship of urinary pyridinium crosslinks to disease extent and activity in osteoarthritis. Br f Rheumatol 1994; 33: 16-9.

29 Astbury C, Bird H A, McLaren A M, Robins S P. Urinary excretion of pyridinium crosslinks of collagen correlated with joint damage in arthritis. Br f Rheumatol 1994; 33: 11-5.

30 Spector T D, James I T, Hall G $M$, Thompson P W, Perrett D, Hart D J. Increased levels of urinary collagen crosslinks in females with rheumatoid arthritis. Clin Rheumatol 1993; 12: 240-4.

31 Seibel M J, Gartenberg F, Silverberg S J, Ratcliffe A, Robins S P, Bilezikian J P. Urinary hydroxypyridinium cross-links of collagen in primary hyperparathyroidism. $f$ Endocrinol Metab 1992; 74: 481-6.

32 Eastell R, Robins S P, Colwell T, Assiri A M A, Riggs B L, Russell R G G. Evaluation of bone turnover in type 1 osteoporosis using biochemical markers specific for both bone formation and bone resorption. Osteoporosis Int 1993; 3: 255-60.

33 Garnero P, Gineyts E, Arbault P, Christiansen C, Delmas P D. Different effects of bisphosphonate and estrogen therapy on free and peptide-bound bone cross-links therapy on free and peptide-bound bone

34 Risteli L, Risteli J, Moniz C. Measuring collagen degradation. Eur $\mathcal{f}$ Clin Invest 1993; 23: 339-40.

35 Delmas P D, Gineyts E, Bertholin A, Garnero P, Marchand F. Immunoassay of pyridinoline crosslink excretion in normal adults and in Paget's disease. $\mathcal{F}$ Bone Miner Res 1993; 8: 643-8.

36 Seyedin S M, Kung V T, Daniloff Y N, et al. Immunoassay for urinary pyridinoline: the new marker for bone resorption. I Bone Miner Res 1993; 8: 635-41.

37 Elomaa I, Virkkunen P, Risteli L, Risteli J. Serum concentration of the cross-linked carboxyterminal telopeptide of type 1 collagen (1CTP) is a useful prognostic indicator in multiple myeloma. $\mathrm{Br} \stackrel{f}{\mathrm{C} \text { Cancer }}$ prognostic indicato

38 Lems W F, Brink H R van den, Gerrits $M I$, Rijn H J M van, Bijlsma $J$ W J. Effect of hormonal replacement therapy on osteocalcin and markers of collagen type 1 turnover in postmenopausal patients with rheumatoid arthritis. Ann Rheum Dis 1993; 52: 335-6. 